\title{
Corneal Transplantation at an Ophthalmological Referral Center in Colombia: Indications and Techniques (2004-2011)
}

\author{
Virgilio Galvis ${ }^{1,2,5}$, Alejandro Tello*,1,2,5, Augusto José Gomez ${ }^{2}$, Carlos Mario Rangel ${ }^{3}$, \\ Angélica María Prada ${ }^{4}$ and Paul Anthony Camacho ${ }^{6}$
}

${ }^{I}$ Centro Oftalmológico Virgilio Galvis, Floridablanca, Colombia

${ }^{2}$ Fundación Oftalmológica de Santander-Clínica Carlos Ardila Lulle (FOSCAL), Floridablanca, Colombia

${ }^{3}$ Fundación Oftalmológica de Santander-Clínica Carlos Ardila Lulle (FOSCAL)- Universidad Industrial de Santander, Floridablanca, Colombia

${ }^{4}$ Centro Oftalmológico Virgilio Galvis, Fundación Oftalmológica de Santander-Clínica Carlos Ardila Lulle (FOSCAL), Floridablanca, Colombia

${ }^{5}$ Health Faculty, Universidad Autónoma de Bucaramanga, Bucaramanga, Colombia

${ }^{6}$ Fundación Oftalmológica de Santander-Clínica Carlos Ardila Lulle (FOSCAL), Colombia

\begin{abstract}
Purpose: To analize changing trends in indications and surgical techniques of corneal transplantation at an ophthalmological tertiary referral center in Colombia over a 7 year period.

Methods: A retrospective analysis was performed of medical records from patients who underwent corneal transplantation surgeries at Fundación Oftalmológica de Santander (FOSCAL) in Bucaramanga, Colombia, between August 2004 and August 2011.

Results: During this period from a total of 450 corneal transplants performed, we had access to 402 medical records (89.4\%). The patients' mean age was 55. Leading indications were: pseudophakic/aphakic bullous kerathopathy (PBK/ABK) (34.6\%), corneal scar (15.7\%), active infectious keratitis (14.4\%) and keratoconus (12.7\%). During the first period (2004-2007) PBK/ABK was the leading indication, followed by stromal opacities and keratoconus. During the second period (2008-2011) PBK/ABK remained the leading indication. Infectious keratitis, however, became the second most common indication. Stromal opacities and keratoconus, moved to third and fourth, respectively. All transplants performed in the first period (2004-2007) were penetrating keratoplasties. In the second period (2008-2011) 18.7\% of the procedures were performed using the Descemet's stripping automated endothelial keratoplasty technique (DSAEK).

Conclusions: Similar to other international results, PBK/ABK was the leading indication for corneal transplantation at our institution. Keratoconus is becoming a less common indication for keratoplasty in our institution. Infectious keratitis remains a frequent indication for corneal transplantation in this geographical area. In our institution we started performing DSAEK in 2009, and it is emerging as the procedure of choice in corneal diseases that involve only the endothelial layers.
\end{abstract}

Keywords: Corneal transplantation, penetrating keratoplasty, endothelial keratoplasty, lamellar keratoplasty, DSAEK.

\section{INTRODUCTION}

Zirm reported the first successful penetrating keratoplasty (PK) in a human in 1906 [1]. Currently the procedure is used in advanced keratoconus, infectious keratitis, corneal dystrophies, stromal opacities, pseudophakic/ aphakic bullous kerathopathy, and others. As posterior lamellar techniques have improved, they have become the first choice in selected cases of endothelial disease due to superior postoperative results, including: better uncorrected visual acuity, lower astigmatism, and lower risk of rejection due to the reduced amount of tissue transplanted $[2,3]$.

*Address correspondence to this author at the Centro Médico Carlos Ardila Lulle. Torre A - Piso 3 - Módulo 7, Floridablanca, Santander, Colombia; Tel: 577 6392626; Fax: 577 6392929; E-mail: alejandrotello@gmail.com
Indications for corneal transplantation have changed over time, especially during the last decade $[4,11]$.

This article describes the most frequent indications of penetrating keratoplasty and DSAEK at Fundación Oftalmológica de Santander (FOSCAL) in Floridablanca, Colombia in addition to the changing trends in the keratoplasty techniques over a seven year period (2004-2011).

\section{MATERIALS AND METHODS}

We made a search in the surgical records at Fundación Oftalmológica de Santander (FOSCAL) in Floridablanca, Colombia, a tertiary referral center for ophthalmologic pathologies in Santander (Colombia) looking for keratoplasty, either PK or DASEK, between August 2004 and August 2011, and we found that 450 keratoplasties were 
performed. We retrieved data of age, gender and type of keratoplasty from the surgical records for all the 450 cases, however we had access only to 402 medical charts for additional data (indication for the procedure), which we obtained retrospectively from those records. To determine the changing trends, we analyzed the data between two time periods, the first between 2004 and 2007 and the second between 2008 and 2011. In the first period, a total of 196 procedures were performed; we were able to analyze 150 $(76.5 \%)$. In the second period, there were 254 corneal transplants executed, of which we analyzed 252 (98.1\%). Data that included age, gender and type of keratoplasties was collected from the surgical books of the 450 procedures. Data concerning indications for the procedure was collected from the medical charts of the 402 we had access to.

Indications were grouped into seven categories: keratoconus, active infectious keratitis (fungal, bacterial, parasitic and polymicrobial), stromal opacities (as a result of infectious keratitis, trauma, or herpetic keratitis), pseudophakic/aphakic bullous kerathopathy (anterior or posterior chamber IOL), regraft (primary or secondary failure, or rejection), corneal dystrophies or degenerations, and others. When a regraft was performed, the indication of the original transplant was collected and analyzed as well.

\section{RESULTS}

A total of 450 transplanted eyes were evaluated. The patients' mean age was 55 and $57 \%$ were men. The demographic data are summarized in Table $\mathbf{1 .}$

Table 1. Patients' Demographic Characteristics

\begin{tabular}{|l|c|c|}
\hline Period & 2004-2007 & 2008-2011 \\
\hline \hline $\mathrm{n}$ & 196 & 204 \\
\hline AGE (MEAN \pm SD) & $53.75 \pm 21.54$ & $52.89 \pm 19.85$ \\
\hline GENDER & & \\
MALE & $55.7 \%$ & $57.1 \%$ \\
FEMALE & $44.3 \%$ & $42.9 \%$ \\
\hline EYES & & 110 \\
RIGHT & 90 & 94 \\
LEFT & 106 & \\
\hline
\end{tabular}

TYPES OF KERATOPLASTY: Of the 450 keratoplasties performed between 2004 and 2011, 403 (89.6\%) were PK and only 47 (10.5\%) were DSAEK. In the first period (2004-2007), a total of 196 (100\%) PK were performed and no DSAEK. However, in 2008-2011, there were $207(82.2 \%)$ PK and $47(18.7 \%)$ DSAEK. When analyzing year by year, there was a rise in the frequency of DSAEK since 2009 with 11 cases that year, 22 cases in 2010, and 14 cases in the first six months of 2011. Of the 139 transplants performed for PBK/ABK, 104 (74.8\%) were PK and 35 (25.1\%) were DSAEK. Between 2004 and 2007 there were $44(100 \%)$ PK and zero DSAEK; conversely, from 2008 to 2011 there were $60(63.2 \%)$ PK and 35 $(36.8 \%)$ DSAEK. Of these, $22(15.9 \%)$ had a posterior chamber intraocular lens (IOL) implanted in the anterior chamber, $110(78.8 \%)$ had an IOL implanted in the posterior chamber, and $7(5.3 \%)$ were aphakic.

INDICATIONS OF KERATOPLASTY: The most frequent indication for keratoplasty between 2004-2011 was PBK/ABK, followed by stromal opacities, active infectious keratitis, keratoconus, corneal dystrophies and degenerations, regraft and others. The last group included: chemical burns ( 3 cases), acute penetrating trauma ( 3 cases), dellen post-pterygium surgery ( 3 cases), perforated ulcer secondary to dry eye syndrome (3 cases), post radial keratotomy ectasia ( 2 cases) and post LASIK ectasia (2 cases).

Between 2004-2007 PBK/ABK was the leading indication for corneal transplant, followed by stromal opacities and keratoconus; during the period of 2008-2011, PBK/ABK remained the leading indication, followed by active infectious keratitis and stromal opacities. Keratoconus was the fourth most common indication. Table 2 shows the distribution of corneal diseases requiring corneal transplants during each time period.

Table 2. Indications for Keratoplasty in 2004-2007 and 20082011

\begin{tabular}{|c|c|c|c|}
\hline Indications & 2004-2007 & 2008-2011 & Total \\
\hline KERATOCONUS & $29(19.3 \%)$ & $22(8.7 \%)$ & $51(12.7 \%)$ \\
\hline STROMAL OPACITIES & $31(20.7 \%)$ & $32(12.7 \%)$ & $63(15.7 \%)$ \\
\hline INFECTIOUS KERATITIS & $12(8.0 \%)$ & $46(18.3 \%)$ & $58(14.4 \%)$ \\
\hline $\mathrm{PBK} / \mathrm{ABK}$ & $44(29.3 \%)$ & $95(37.7 \%)$ & $139(34.6 \%)$ \\
\hline REGRAFT & $11(7.3 \%)$ & $20(7.9 \%)$ & $31(7.7 \%)$ \\
\hline CORNEAL DYSTROPHY & $11(7.3 \%)$ & $19(7.5 \%)$ & $30(7.5 \%)$ \\
\hline OTHERS & $12(8.0 \%)$ & $18(7.1 \%)$ & $30(7.5 \%)$ \\
\hline TOTAL & 150 & 252 & 402 \\
\hline
\end{tabular}

Fungal keratitis (32.8\%) was the most recurrent etiology for corneal transplant when active infectious keratitis was the indication, followed by polymicrobial $(31.0 \%)$ and bacterial keratitis $(12.1 \%)$. There was one case of herpetic keratitis. The etiology was not identified in 13 cases $(22.4 \%)$.

Infectious ulcer $(37.9 \%)$, trauma $(29.9 \%)$, and herpetic keratitis $(10.3 \%)$ were the causes of stromal opacities affecting the visual axis. The cause of the leukoma was not identified in the remaining cases.

There were a total of 31 cases of regraft; the original indications for keratoplasty were PBK/ABK (32\%), Fuchs' endothelial corneal dystrophy (13\%), corneal ectasia (13\%), infectious keratitis (6\%), stromal opacities $(6 \%)$ and acute penetrating trauma $(3 \%)$, the original indication was not identified in the remaining cases. The regraft was performed because of primary failure in 2 cases $(6 \%)$, secondary failure in 8 cases (26\%), and allograft rejection in 14 cases (45.2\%). In the remaining cases, it was not possible to establish the cause of corneal transplant failure. 
Table 3. Recently Published Studies on Keratoplasty Indications

\begin{tabular}{|c|c|c|c|c|c|c|c|c|c|c|}
\hline & \multicolumn{2}{|c|}{$\begin{array}{c}\text { New Zealand } \\
n=2,253 \\
\text { Cunningham } \text { et al. }[8]\end{array}$} & \multicolumn{2}{|c|}{$\begin{array}{c}\text { China } \\
\mathrm{n}=\mathbf{5 , 3 1 6} \\
\text { Xie } \text { et al. } \text { [11] }\end{array}$} & \multicolumn{2}{|c|}{$\begin{array}{c}\text { Scotland } \\
\mathrm{n}=921 \\
\text { Ting } \text { et al. } \text { [6] }\end{array}$} & \multicolumn{2}{|c|}{$\begin{array}{c}\text { Canada } \\
\mathrm{n}=3,571 \\
\text { Sheldon } \text { et al. } \text { [5] }\end{array}$} & \multicolumn{2}{|c|}{$\begin{array}{c}\text { Hungary } \\
\quad \mathrm{n}=\mathbf{4 0 2} \\
\text { Módis et al. }[4]\end{array}$} \\
\hline & \multicolumn{2}{|c|}{ 2000-2009 } & \multicolumn{2}{|c|}{$1996-2007$} & \multicolumn{2}{|c|}{ 2001-2010 } & \multicolumn{2}{|c|}{$1995-2005$} & \multicolumn{2}{|c|}{ 2006-2009 } \\
\hline Keratoconus & 938 & $41,6 \%$ & 674 & $12,7 \%$ & 264 & $28,7 \%$ & 592 & $16,6 \%$ & 60 & $14,9 \%$ \\
\hline Regraft & 391 & $17,4 \%$ & 246 & $4,6 \%$ & 177 & $19,2 \%$ & 755 & $21,1 \%$ & 74 & $18,4 \%$ \\
\hline Keratitis & 180 & $8,0 \%$ & 2387 & $44,9 \%$ & 106 & $11,5 \%$ & 294 & $8,2 \%$ & 22 & $5,5 \%$ \\
\hline Stromal opacities^ & 94 & $4,2 \%$ & 1195 & $22,5 \%$ & 21 & $2,3 \%$ & 573 & $16,0 \%$ & 74 & $18,4 \%$ \\
\hline Others & \multicolumn{2}{|c|}{ 1999-2009 } & \multicolumn{2}{|c|}{ 2004-2009 } & \multicolumn{2}{|c|}{ 2001-2010 } & \multicolumn{2}{|c|}{$1985-2011$} & \multicolumn{2}{|c|}{ 2004-2011 } \\
\hline Keratoconus & 5469 & $24,0 \%$ & 714 & $38,4 \%$ & 306 & $25,5 \%$ & 6789 & $29,6 \%$ & 51 & $12,7 \%$ \\
\hline $\mathrm{PBK} / \mathrm{ABK}$ & 3597 & $15,8 \%$ & 218 & $11,7 \%$ & 175 & $14,6 \%$ & 4478 & $19,6 \%$ & 139 & $34,6 \%$ \\
\hline Fuchs`' Distrophy & 4434 & $19,5 \%$ & 15 & $0,8 \%$ & 254 & $21,2 \%$ & 2790 & $12,2 \%$ & 30 & $7,5 \%$ \\
\hline Regraft & 3318 & $14,6 \%$ & 197 & $10,6 \%$ & 84 & $7,0 \%$ & 4650 & $20,3 \%$ & 31 & $7,7 \%$ \\
\hline Keratitis & 1885 & $8,3 \%$ & 188 & $10,1 \%$ & 156 & $13,0 \%$ & 1254 & $5,5 \%$ & 58 & $14,4 \%$ \\
\hline
\end{tabular}

Including: Corneal stromal distrophies, corneal degenerations, corneal opacities.

\section{DISCUSSION}

According to our knowledge, this is the first study that analyzes the indications and techniques of corneal transplantation in Colombia. Fundación Oftalmológica de Santander (FOSCAL) is an ophthalmological tertiary referral center in Santander, Colombia, which serves a population of more than two million inhabitants. Given the large population, the indications for penetrating keratoplasty and endothelial keratoplasty may be representative of national trends.

We performed a literature review using PubMed to identify similar studies that reported indications for corneal transplants covering the period between 1995 to at least 2009 in order to compare their findings to our study. Articles that analyzed years outside the aforementioned period were excluded because of the changes in diagnostics, therapeutics, and surgical techniques that have arisen in recent years (Table 3).

In our study, PBK/ABK was the primary indication for corneal transplant, similar to findings reported in Hungary and Canada. It corresponded to $30.9 \%$ of all cases, slightly higher than the reported percentages in Hungary (28.9\%) and Canada $(22.1 \%)[4,5]$. On the other hand, keratoconus was the first cause of keratoplasty in cases performed in New
Zealand (41.6\%), Iran (38.4\%), Australia (29.6\%), Scotland $(28.7 \%)$, Germany $(25.5 \%)$, and the United Kingdom (24\%) $[6-10,12]$. We found that keratoconus was the fourth most common indication in the complete seven-year period, but it was the third indication between 2004-2007 and fell to fourth place between 2008-2011. This might be explained by FOSCAL's introduction of corneal collagen cross-linking mediated by UV light during the second period.

Infectious keratitis is reported as the leading indication for keratoplasty in China, accounting for $44.9 \%$ of cases [11]. We found that infectious keratitis was the third most common indication for keratoplastly and represented only $14.4 \%$ of our cases, consistent with the percentages reported in Scotland (11.5\%) [6], Iran (10.1\%) [9], and Germany (13\%) [10]. Analyzing each time period separately, infectious keratitis accounted for $8 \%$ and $18.3 \%$ of indications between 2004-2007 and 2008-2011, respectively. The apparent increase in infectious keratitis cases could be explained by the lower number of medical records available to be included in the study from the first period of time. The emergency department handled a high number of these cases, suggesting that they corresponded to infectious keratitis and not PBK/ABK or keratoconus.

DSAEK surgeries were introduced in our institution during the second period, and they represented $18.7 \%$ of all 
types of keratoplasty performed in the period 2008-2011. This is consistent with other studies that demonstrate a rise in the number of lamellar techniques since their introduction in recent years $[6,8]$. Endothelial keratoplasty increased from $0 \%$ in the period of $2001-2005$ to $9.1 \%$ in the period of 2006-2010 in Scotland [6]. In the United Kingdom, the incidence rose from $0.1 \%$ between $1999-2000$ to $23 \%$ between 2008-2009 [7]. Lamellar keratoplasties accounted for $8.3 \%$ of all corneal transplants in the period of 20002009 in New Zealand, but in 2009 they represented $32.3 \%$ of all types of keratoplasty [8]. The increasing trend in DSAEK surgeries performed might be related to the fact that pathologies affecting only the posterior layers of the cornea represent a large percentage of keratoplasty indications (PBK/ABK and FECD). As such, surgeons are gaining experience with this technique, which has lower rejection rates and better visual outcomes [2,3].

\section{CONFLICT OF INTEREST}

The authors confirm that this article content has no conflict of interest.

\section{ACKNOWLEDGEMENTS}

Declared none.

\section{REFERENCES}

[1] Zirm EK. Eine erfolgreiche totale Keratoplastik (A successful total keratoplasty). 1906. Refract Corneal Surg 1989; 5: 258-61.

[2] Ratanasit A, Gorovoy MS. Long-term results of Descemet stripping automated endothelial keratoplasty. Cornea 2011; 30: 1414-8.

[3] Lee WB, Jacobs DS, Musch DC, Kaufman SC, Reinhart WJ, Shtein RM. Descemet's stripping endothelial keratoplasty: safety and outcomes: a report by the American Academy of Ophthalmology. Ophthalmology 2009; 116: 1818-30.

[4] Módis L Jr, Szalai E, Facskó A, Fodor M, Komár T, Berta A. Corneal transplantation in Hungary (1946-2009). Clin Exp Ophthalmol 2011; 39: 520-5.

[5] Sheldon CA, McCarthy JM, White VA. Correlation of clinical and pathologic diagnoses of corneal disease in penetrating keratoplasties in Vancouver: a 10-year review. Can J Ophthalmol 2012; 47: 5-10.

[6] Ting DS, Sau CY, Srinivasan S, Ramaesh K, Mantry S, Roberts F. Changing trends in keratoplasty in the West of Scotland: a 10-year review. Br J Ophthalmol 2012; 96: 405-8.

[7] Keenan TD, Jones MN, Rushton S, Carley FM. National health service blood and transplant ocular tissue advisory group and contributing ophthalmologists (ocular tissue advisory group audit study 8): Trends in the indications for corneal graft surgery in the United Kingdom: 1999 through 2009. Arch Ophthalmol 2012; 130: 621-8.

[8] Cunningham WJ, Brookes NH, Twohill HC, et al. Trends in the distribution of donor corneal tissue and indications for corneal transplantation: the New Zealand National Eye Bank Study 20002009. Clin Exp Ophthalmol 2012; 40: 141-7.

[9] Zare M, Javadi MA, Einollahi B, et al. Changing indications and surgical techniques for corneal transplantation between 2004 and 2009 at a tertiary referral center. Middle East Afr J Ophthalmol 2012; 19: 323-9.

[10] Wang J, Hasenfus A, Schirra F, Bohle RM, Seitz B, Szentmáry N. Changing indications for penetrating keratoplasty in Homburg/Saar from 2001 to 2010--histopathology of 1,200 corneal buttons Graefes Arch Clin Exp Ophthalmol 2013; 251(3): 797-802.

[11] Xie L, Qi F, Gao H, Wang T, Shi W, Zhao J. Major shifts in corneal transplantation procedures in north China: 5316 eyes over 12 years. Br J Ophthalmol 2009; 93: 1291-5.

[12] Williams KA, Lowe MT, Keane MC, Jones VJ, Loh RS, Coster DJ, Eds. The Australian Corneal Graft Registry: 2012 Report. Adelaide, Australia: Snap Printing 2012; vol. 182: pp. 85-6. 